The Priestman oil engine performs its work admirably, and proves to be an economical source of power. Although I have spoken of oil engines only in connection with water supply, it must not be assumed that $I$ intend to imply that they may not be usefully applied to various other purposes, such, for instance, as sewage pumping, etc, nor must it be forgotten that there are other oil engines

\section{DESCRIPTION OF AN INSANITARY AREA IN SOUTHAMPTON.}

By A. Wellesley Harris, D.P.II, etc., M.O.H. of Southampton.

THE description of the insanitary Area, as regard situation and boundaries, is fully given in the Representation. This, however, does not give

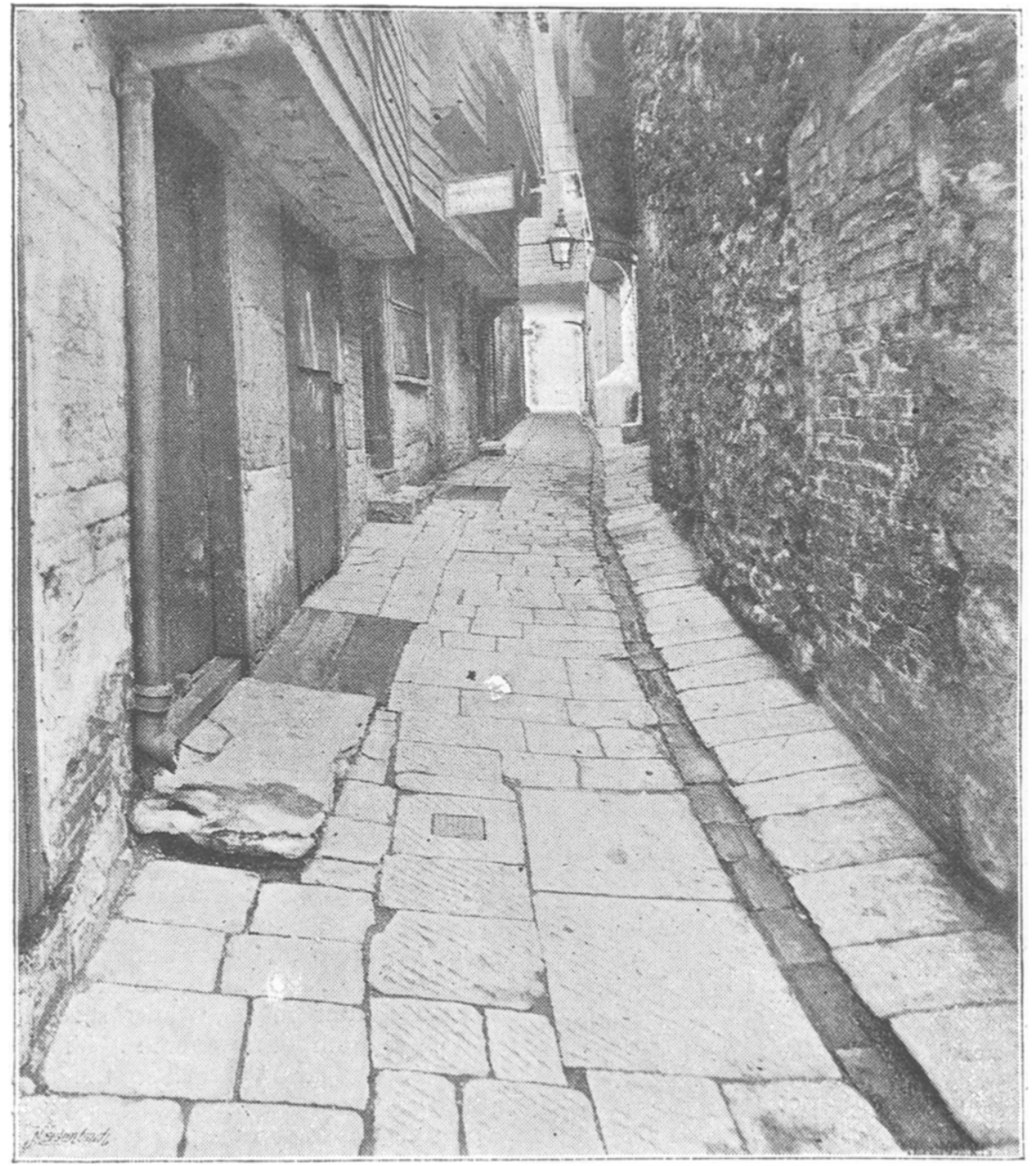

besides Priestman's; but I have confined my remarks to that engine, and to that one use of it, because I was desirous of not stating anything with which $I$ was not practically acquainted; whilst I bave had practical experience with that engine and its adaption to that particular purpose, and am well satisfied with the work it performs.

A vote of thanks to Dr. Ashby for his valuable paper was passed unanimously. any idea of the terrible condition under which the inhabitants are now living.

The whole area has upon it 128 houses of most insanitary type, being arranged in narrow streets out of which lead long narrow passages passing to "blind "courts without proper light and ventilation. Some of the houses are perfect hovels; totally unfit for habitation.

Southampton at present possesses, in a fine state of preservation, and for a large extent, the remains 
of the old town walls, and there is no doubt every available space within these was secured to erect buildings upon, which explains their crowded and curious arrangement.

Some of the later buildings appear to have been erected in the back gardens of the older houses.

I was able to photograph some of the well-known courts and streets, two re-productions of which are appended, and I trust this will soon be the only method of viewing them. to contain some fine Norman work. The lane is extremely narrow, being on the average six feet wide.

Only one house remains occupied, and here artificial light is used during the day.

The second illustration is that of Castle Lane, leading out of Simnel Street. The houses on the right hand side may be classed as insanitary hovels.

An International Exhibition of Hygiene is to be held at Paris, from May 15 th to September 15 th, $x 895$.

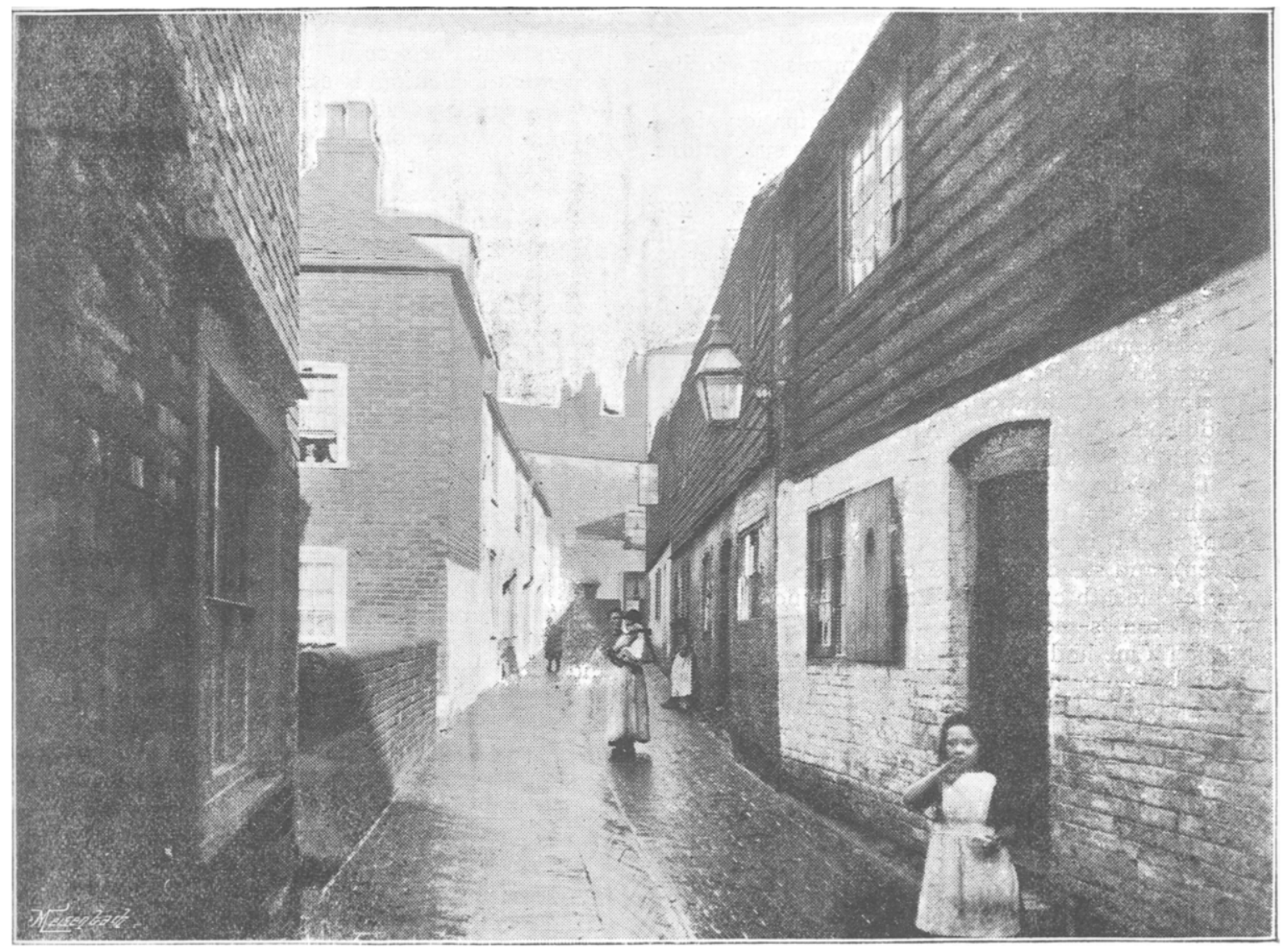

These photographs do not show the worst places, views of which it is too difficult to obtain.

The first picture is that of Blue Anchor Lane. The illustration shows the upper portion leading to Pepper Alley.

It is a narrow winding lane, containing houses of the Norman period. The houses are undoubtedly picturesque but most insanitary. Two years ago they were occupied as Common Lodging Houses, receiving a large number of tramps.

Their structure is principally of wood. The last house in the lane, "King John's Palace," is said
Diphtheritic Mempranes BV Post.-The French Postal Authorities have recently published regulations for the transmission of false membranes, etc., by post in France. They may only be sent in a thick glass bottle, tightly corked and sealed, surrounded with wadding and put into a solid metal box, which in its turn is to be enclosed in a well-fitting wooden box. This must be legibly addressed and labelled "Diphtheritic false membranes," and may only be sent to the Institut Pasteur or to one of the recognized provincial laboratories. 